\title{
PENGGUNAAN LITIUM SILIKAT SEBAGAI KONSOLIDAN ANORGANIK PADA BATU BATA MELALUI UJI PEMBUATAN MORTAR
}

\author{
Farida, Nahar Cahyandaru, Nuryono \\ Departemen Kimia, FMIPA, Universitas Gadjah Mada \\ Balai Konservasi Borobudur, Magelang \\ faridasoedarsono@gmail.com,nhrcahyandaru@yahoo.com,nuryono_mipa@ugm.ac.id
}

\begin{abstract}
Abstrak : Penggunaan litium silikat hasil sintesis dari litium hidroksida dan silika sebagai konsolidan pada batu bata telah dipelajari melalui uji pembuatan mortar. Litium silikat disintesis melalui proses sol gel pada temperatur $70{ }^{\circ} \mathrm{C}$ dengan menggunakan bahan baku litium hidroksida $(\mathrm{LiOH})$ dan fumed silica $(\mathrm{SiO} 2)$ dengan rasio mol 4:1. Konsolidasi dilakukan dengan cara mencampur serbuk batu bata dengan larutan litium silikat 10\% b/v. Karakterisasi hasil konsolidasi dilakukan dengan penentuan komposisi kimia menggunakan X-ray Fluorescence (XRF) dan pengukuran kekerasan mortar dalam skala Mohs. Hasil penelitian menunjukkan bahwa litium silikat berhasil disintesis dengan rendemen $22,78 \%$ dan kadar Si $(35,78 \pm 0,21) \%$. Kemampuan konsolidasi litium silikat pada batu bata ditunjukkan dengan sifat fisik mortar yang sama dengan batu bata sebelum dikonsolidasi. Sifat fisik tersebut meliput warna merah bata, kekerasan 2-3 skala Mohs di kisaran 0,61-1,49 GPa), dan kandungan Si meningkat 2,13\% dibandingkan batu bata sebelum dikonsolidasi.
\end{abstract}

Kata kunci : batu bata, konsolidasi, litium silikat, sol-gel

\begin{abstract}
The use of synthetic lithium silicates from lithium hydroxide and silica as consolidated in bricks through mortar testing has been studied. Lithium silicate is was synthesized through sol gel at $70 \mathrm{oC}$ using lithium hydroxide $(\mathrm{LiOH})$ and fumed silica $(\mathrm{SiO} 2)$ as raw materials with a mol ratio of 4:1. Consolidation was done by mixing the brick powder with $10 \% \mathrm{w} / \mathrm{v}$ of lithium silicate solution. Characterization of the modified compound using X-ray Fluorecence (XRF) and mortar aging in Mohs scale. The results showed that lithium silicate was successfully synthesized with $22.78 \%$ yield and Si content of $35.78 \pm 0.21 \%$. The ability of lithium silicate to consolidate bricks gave the same physical properties as mortar of brick before consolidation. The color iwas red brick, hardness 2-3 Mohs scale was in a range of $(0.61-1,49 \mathrm{GPa})$, and Si content increased, 2.13\% compared to brick before being consolidated.
\end{abstract}

Keywords : brick, consolidation, lithium silicate, sol-gel

\section{A. Latar Belakang}

Cagar Budaya menurut Undang-Undang Republik Indonesia Nomor 11 Tahun 2010 merupakan warisan budaya bersifat kebendaan berupa Benda Cagar Budaya, Bangunan Cagar Budaya, Struktur Cagar Budaya, Situs Cagar Budaya, dan Kawasan Cagar Budaya di darat dan/atau di air yang perlu dilestarikan keberadaannya karena memiliki nilai yang penting bagi sejarah, ilmu pengetahuan, pendidikan, agama, dan/atau kebudayaan melalui proses penetapan. Bangunan Cagar Budaya juga dijelaskan sebagai susunan binaan yang terbuat dari benda alam atau buatan manusia untuk memenuhi kebutuhan

ruang berdinding dan/atau tidak berdinding dan beratap.

Balai Konservasi Borobudur sebagai pusat pengembangan dan kajian konservasi di bawah Kementerian Pendidikan dan Kebudayaan memiliki tugas untuk menjaga kelestarian Cagar Budaya. Kajian konservasi yang dilakukan berupa konsolidasi dengan bahan kimia, baik dari hasil isolasi bahan alam maupun hasil sintesis di laboratorium. Konsolidasi dapat dilakukan pada material penyusun bangunan Cagar Budaya, seperti kayu dan batuan untuk memperkuat strukturnya (Anonim, 2015). 
Batu bata merupakan salah satu material penyusun bangunan Cagar Budaya di Indonesia misalnya, di wilayah Jawa Timur, Jawa Barat, Bali, Jambi, dan Sumatera Barat. Menurut Martinez dkk. (2016), batu bata mudah mengalami destruksi atau pelapukan jika dibandingkan dengan material bangunan lainnya, karena porositasnya yang relatif tinggi antara $11-40 \%$ pada bangunan kontemporer, dan 30-38\% pada bangunan bersejarah. Porositas yang terinterkoneksi dapat memfasilitasi transport air dan agen pendestruksi masuk ke dalam matriks batu bata, sehingga semakin mudah mengalami destruksi. Salah satu contoh kerusakan dan pelapukan batu bata menurut Swastikawati (2011), yaitu pada bata pengganti Candi Brahu di Trowulan, Jawa Timur akibat proses fisik, mekanik, biologis, dan kimia.

Konsolidasi terhadap batuan yang lapuk telah banyakdilakukan, sebagaicontohnyadenganmenggunakan tetra-etil orto silikat (TEOS), methyltrimethoxysilane (MTMOS), Paraloid B72 (kopolimer etil-metakrilat), dan Tegovakon. Menurut Martinez dkk. (2016), TEOS sebagai konsolidan memiliki kelemahan, yaitu tidak dapat diaplikasikan pada batuan dengan kelembaban tinggi karena sifatnya yang hidrofobik. Pada kondisi tersebut hidrolisis terjadi secara cepat dan meninggalkan residu Si-OH yang menyebabkan keretakan. Pada kondisi dengan kelembaban rendah; material yang terhidrolisis tidak retak, namun terjadi evaporasi monomer yang tinggi, sehingga mereduksi jumlah akhir dari polimer yang terendapakan dalam substrat batuan.

Pinto dan Rodrigues (2008) melaporkan bahwa konsolidasi dengan MTMOS belum maksimal karena afinitas kimia yang rendah antara kalsit dengan silika setelah kondensasi alkoksilan dan cenderung retak saat pengeringan karena kerusakan gel. Penggunaan Paraloid B72 sebagai cat pelapis dalam konservasi benda seni dan Tegovakon sebagai etil silikat yang khusus digunakan untuk konsolidasi material yang banyak mengandung Si; misalnya batu bata, ternyata menyebabkan warna batuan menjadi lebih gelap (Agan, 2016).

Litium silikat mengatasi kekurangan etil silikat dengan membentuk litium karbonat dan kalsium silikat selain pembentukan silika. Konsolidan ini dapat diterapkan pada batu dengan kondisi basah atau lembab sehingga dapat mengatasi masalah ketidakcocokan yang dihadapi dengan silan, dimana telah diterapkan pada substrat kalsit (Wheeler, 2005).

Kelompok hidrofobik tidak terdapat pada litium silikat, sehingga reaksi dapat berlangsung sepenuhnya dalam lingkungan hidrofilik dan berpotensi besar sebagai konsolidan untuk permukaan basah. Konsolidasi yang telah dilakukan ini terkait dengan empat lokasi, yaitu tuff vulkanik di Selandia Baru, gua kapur di Kepulauan Chatham, kalsit terkonsolidasi gundukan pasir di Australia Barat, dan konglomerat berbutir halus di Uluru, Australia Tengah. Ketidakcocokan antara kelembaban dan konsolidan, antara kalsit dan silan telah diatasi dengan sistem saat ini (Thorn, 2012). Litium silikat juga menjadi cat yang paling efektif untuk menjaga kekuatan batu dan penampilan batuan. Hal ini telah dibuktikan pada penelitian konsolidasi batuan kapur Sanliurfa oleh Agan (2016).

Berdasarkan pada kelebihan konsolidan litium silikat yang telah disebutkan di atas maka dalam paper ini dilaporkan efek konsolidasi pada sifat batu bata melalui uji pembuatan mortar. Kekerasan dan komposisi kimia dalam mortar digunakan sebagai parameter keberhasilan konsolidasi. Litium silikat disintesis dari litium hidroksida monohidrat (LiOH.H2O), aerosil (SiO2), dan asam sitrat (C6H8O7) yang berperan sebagai agen khelat.

\section{B. Metode}

\section{Bahan}

Bahan kimia yang digunakan pada penelitan ini meliputi serbuk asam sitrat (C6H8O7), serbuk litium hidoksida monohidrat (LiOH.H2O), dan indikator $\mathrm{pH}$ universal dari MERCK, SiO2 (fumed silica), akuades, dan kertas saring Whattman No. 40. Sampel batu bata yang digunakan berasal dari lingkungan sekitar Balai Konservasi Borobudur, Magelang.

\section{Alat}

Alat yang digunakan pada penelitian ini meliputi, peralatan gelas, stirrer Thermo Scientific, timbangan Mettler Toledo AB204-5, magnetic stirrer dan, termometer $\mathrm{Hg}$. Selain itu digunakan juga, $\mathrm{pH}-$ meter OAKTON PC650, muffle furnace, XRF Portabel (Olympus DP-2000 High Count Rate), oven Barnstead Thermolyne 1400 furnace, mortar dan alu dan penyaring bertingkat. 


\section{Cara Kerja}

\subsection{Preparasi sampel batuan}

Sampel batu bata ditumbuk halus dan disaring menggunakan saringan bertingkat dengan ukuran serbuk bata 0,$063 ; 0,125 ; 0,250 ; 0,500 ;$ dan 1,000 mm. Serbuk bata dengan berbagai ukuran tersebut dibuat mortar dengan komposisi10 g yang komposisinya disesuaikan dengan komposisi Fuller pada Tabel IV.1.

Tabel IV.1 Ukuran dan komposisi mortar

\begin{tabular}{|c|c|c|c|c|c|}
\hline Ulursh (mm) & 4,063 & $0,125-0,250$ & $0,2500,500$ & $0,500-1,000$ & $<1,000$ \\
\hline Mass: (D) & 0,363 & D,996 & 1,279 & 1,525 & 1,87 \\
\hline
\end{tabular}

\subsection{Sintesis Litium Silikat}

Litium silikat disintesis dari $\mathrm{LiOH}$, asam sitrat dan SiO2 dengan rasio mol 12:4:3. Sintesis dilakukan melalui proses sol-gel yang dimulai dengan pelarutan padatan litium hidroksida monohidrat (LiOH.H2O) sebanyak 7,0078 g, ke dalam 170 mL akuades. pH campuran yang telah homogen diatur hingga mencapai 8,5 menggunakan asam sitrat 0,1 mol L-1 dan konsentrasi $\mathrm{LiOH}$ dalam larutan adalah 0,3 mol L-1. Fumed silica sebanyak 2,523 g ditambahkan ke dalam campuran tersebut kemudian dipanaskan pada temperatur 70 oC. Pemanasan disertai dengan pengadukan hingga terbentuk gel transparan. Litium silikat dibuat dengan perbandingan jumlah mol LiOH.H2O dan SiO2 sebesar 4:1.Gel transparan dikeringkan pada temperatur $150{ }^{\circ} \mathrm{C}$, dan dikalsinasi pada temperatur 675 oC selama 4 jam hingga terbentuk padatan putih (Wu dkk., 2009).

\subsection{Pembuatan dan karakterisasi mortar batu bata}

Serbuk batu bata dengan massa $10 \mathrm{~g}$ dimasukan dalam gelas beker, kemudian ditambah larutan litium silikat $10 \% \mathrm{~b} / \mathrm{v}$ sebanyak 1,5 mL, yang dihasilkan dari pelarutan litium silikat dengan akuades. Campuran tersebut dimasukan ke dalam cetakan berbentuk kubus $(2 \times 2 \times 2 \mathrm{~cm} 3)$ dan dibiarkan mengeras selama 15 hari. Litium silikat hasil sintesis dan mortar yang sudah mengeras dianalisis kandungan unsurnya dengan menggunakan XRF dengan 3 kali pengulangan. Selain itu, mortar diukur tingkat kekerasannya dalam skala Mohs.

\section{Hasil dan Pembahasan}

Litium silikat disintesis menggunakan material dasar LiOH2.H2O (litium hidroksida monohidrat) dan SiO2 (fumed silica) melalui proses sol-gel. Perbandingan mol LiOH.H2O dan SiO2 yang digunakan dalam penelitian ini adalah 4:1. Tahap kalsinasi atau pengeringan litium silikat dilakukan pada temperatur $675^{\circ} \mathrm{C}$ selama 4 jam dilakukan untuk mendapatkan serbuk litium silikat. Hasil sintesis litium silikat yang diperoleh ditunjukkan pada Gambar V.1.

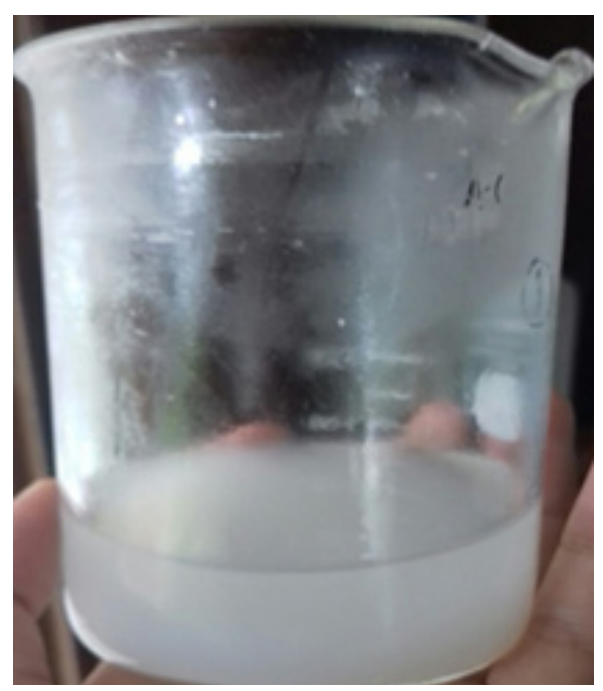

Gambar V.1 Koloid litium silikat

Gel yang dihasilkan pada penelitian ini tidak begitu transparan dimana masih terdapat endapan putih berupa koloid yang ditunjukkan pada Gambar V.1, sedangkan pada penelitian yang sama oleh Agustina (2016) dan Wu dkk. (2009), diperoleh gel transparan. Begitu juga pada serbuk litium silikat yang dihasilkan tidak berwarna putih, namun berwarna putih kehitaman. Adanya koloid menggambarkan bahwa gel belum sepenuhnya terbentuk. Hal ini diakibatkan oleh pemanasan yang tidak berlangsung secara kontinyu, sedangkan pada penelitian sebelumnya dilakukan pemanasan secara kontinyu oleh Agustina (2016).

Tabel V.1 Komposisi kimia penyusun litium silikat

\begin{tabular}{ll}
\multicolumn{2}{l}{ Parameter } \\
$\mathrm{Si}$ & 35,78 \\
$\mathrm{SiO} 2$ & 76,55 \\
$\mathrm{Ti}$ & 0,06 \\
$\mathrm{Fe}$ & 0,06 \\
$\mathrm{Ag}$ & 0,01 \\
$\mathrm{Cd}$ & 0,01
\end{tabular}

Berdasarkan hasil karakterisasi litium silikat menggunakan XRF diperoleh unsur silika (Si) sebagai penyusun utamanya dengan komposisi (35,78 \pm $0,21) \%$. Hal ini menunjukkan bahwa litium silikat dapat digunakan sebagai konsolidan pada batuan berbasis silika 
seperti batu bata. Kandungan Si yang cukup banyak akan meningkatkan kekuatan bahan agregat litium silikat dalam mortar. Jika dibandingkan dengan komposisi Si pada bata yang belum dikonsolidasi, yaitu $(27,69 \pm 0,54) \%$; maka terjadi kenaikan kandungan Si dalam mortar. Kandungan Si yang banyak akan memperkuat struktur mortar yang padat. Pemadatan mortar disebabkan karena proses hidrolisis (dengan air di pori-pori dan uap air di atmosfer), membentuk silanol (Si-OH) dan litium hidroksida sesuai dengan reaksi di bawah ini:

$\mathrm{Li}_{4} \mathrm{SiO}_{4}+4 \mathrm{H}_{2} \mathrm{O} \rightarrow \mathrm{Si}(\mathrm{OH})_{4}+4 \mathrm{LiOH}$

Komposisi unsur $\mathrm{Fe}$ (besi) sebesar (7,86 \pm $0,16) \%$ pada mortar menyebabkan warna merah seperti halnya warna batu bata. Hal ini sesuai dengan pendapat Lumantarna (2012), bahwa bahan pewarna bata yang utama adalah besi oksida sebagai mineral besi. Pembakaran mineral besi pada suhu tinggi menyebabkan munculnya warna merah atau merah kecoklatan akibat pembentukan hematit (Fe2O3). Kehadiran hematit pada struktur bata akhir sebagian besar dipengaruhi oleh proporsi oksida besi dalam bahan baku tanah liat. Jika proporsi oksida besi rendah, semua $\mathrm{Fe} 3+$ yang tersedia digunakan oleh mineral lain yang terbentuk selama pembakaran suhu tinggi, dan sebaliknya kekurangan hematit pada struktur bata akhir akan menyebabkan pembentukan batu bata berwarna coklat muda atau kuning. Distribusi oksida besi yang tinggi menyebabkan pembentukan hematit dalam struktur bata akhir karena Fe3+ yang tersisa yang belum digabungkan oleh mineral lain ada, dan oleh karena itu batu bata berwarna kemerahan terbentuk.

Menurut Sandrolini dkk. (2012), silika gel mengendap di dalam mikrostruktur material berpori melalui proses dehidrasi/kondensasi sehingga mortar semakin kuat dan memadat (Gambar V.3).

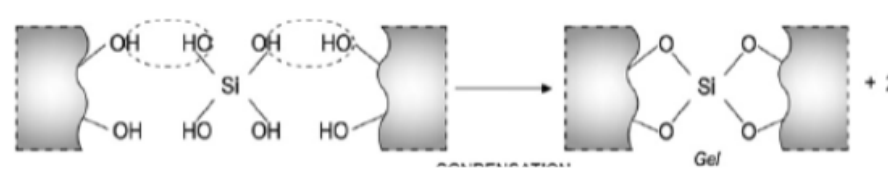

Gambar V.3 Reaksi kondensasi silika gel

Reaksi yang terjadi selama pembentukan litium silikat adalah sebagai berikut,
Berdasarkan stoikiometri reaksi pembentukan litium silikat, maka dapat diperoleh massa Li_4 SiO_4 yang terbentuk sebesar $5 \mathrm{~g}$ sedangkan dari hasil eksperimen diperoleh 1,1389 g produk. Oleh karena itu, nilai rendemen litium silikat yang terbentuk sebesar 22,89\% dan termasuk rendemen yang rendah. Hal ini dikarenakan pembentukan gel yang tidak sempurna.

Tidak adanya sisa reaktan pada permukaan mortar juga dibuktikan dengan hasil konsolidasi yang ditunjukkan pada Gambar V.2, dimana tidak ada bercak putih yang terbentuk pada permukaan mortar. Performance mortar tersebut mengindikasikan bahwa litium silikat dengan rasio mol LiOH:SiO2 4:1 berhasil menjadi konsolidan yang baik bagi batu bata. Agustina (2016), melaporkan bahwa sisa reaktan yang terbentuk menyebabkan adanya bercak-bercak putih pada permukaan mortar andesit.

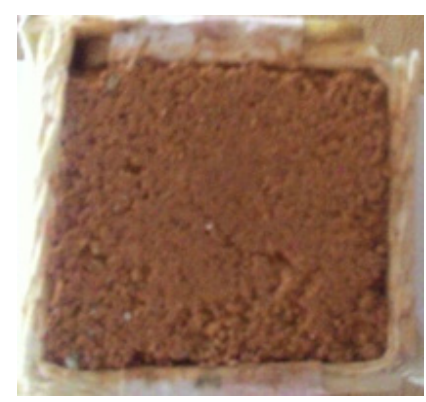

\section{Gambar V.2 Mortar hasil konsolidasi}

Secara fisik diperoleh mortar dengan skala kekerasan batuan 2-3 skala Mohs atau setara dengan 0,61-1,49 GPa menurut Whitney dkk. (2007). Ukuran skala Mohs yang diperoleh sudah sesuai dengan kekerasan batu bata sebelum dikonsolidasi (2-3 Mohs), sehingga dapat dikatakan litium silikat berhasil menjadi konsolidan yang baik bagi batu bata.

\section{Penutup \\ 1. Kesimpulan}

Hasil sintesis litium silikat dengan bahan baku litium hidroksida $(\mathrm{LiOH})$ dan fumed silica (SiO2) dengan rasio mol 4:1 berupa padatan serbuk berwarna putih 2 Ho dengan noda-noda hitam dan diperoleh rendemen hasil $22,78 \%$. Karakterisasi dengan XRF menunjukkan bahwa komponen utama produk adalah $\mathrm{Si}$ dengan komposisi $(35,78 \pm 0,21) \%$. Karakteristik mortar batu bata hasil konsolidasi dengan litium silikat, yaitu padatan berwarna merah bata dengan kekeraan 2-3 skala Mohs (0,611,49 GPa). Komponen utama mortar adalah Si dengan 
komposisi yang diperoleh dari karakterisasi dengan XRF $(28,28 \pm 0,24) \%$.

\section{Saran}

Untuk mengetahui efektifitas konsolidan sebaiknya dilakukan analisis lanjutan mengenai efek konsolidasi litium silikat pada batu bata dengan parameter sifat fisik-mekanik, kekuatan, dan struktur mikronya.

\section{DAFTAR PUSTAKA}

Agan, C., 2016, A Preliminary Study on The Conservation and Polishing Performance of Sanliurfa Limestones as a Traditional Building Material. Bull Eng. Geol. Environ., 75(1), 13-25.

Agustina, M., 2016, Sintesis Litium Silikat untuk Konsolidasi Batu Andesit di Balai Konservasi Borobudur, Skripsi, Departemen Kimia Universitas Islam Indonesia, Yogyakarta.

Anonim, 2010, Undang-Undang Republik Indonesia Nomor 11 Tahun 2010 tentang Cagar Budaya.

Anonim, 2015, Peraturan Menteri Pendidikan dan Kebudayaan Republik Indonesia Nomor 29 Tahun 2015.

Lumantarna, R., 2012, Material Characterisation of New Zealand's Clay Brick Unreinforced Masonry Buildings, Thesis, Department of Civil and Environmental Engineering The University of Auckland, New Zealand.

Martinez, P., Soto, M., Zunino, F., Stuckrath, C., and Lopez, M., 2016, Effectiveness of Tetra-
Ethyl-Ortho-Silicate (TEOS) Consolidation of Fired-Clay Bricks Manufactured with Different Calcination Temperatures, Constr. Build. Mater., 106, 209-217.

Pinto, A.P.F. \& Rodrigues, J.D., 2008. Stone consolidation: The role of treatment procedures. J. Cult. Herit., 9(1), 38-53.

Sandrolini, F., Franzoni, E., and Pigino, B., 2012, Ethyl Silicate For Surface Treatment of Concrete - Part I: Pozzolanic Effect of Ethyl Silicate, Cem. Concr. Compos., 34(3), 306-312.

Swastikawati, A., 2011, Standar Pengujian Kualitas Bata Pengganti, Jurnal Konservasi Cagar Budaya Borobudur, 5(5), 4.

Thorn, A., 2012, Lithium Silicate Consolidation of Wet Stone and Plaster, Proceeding 12th International Congress on The Deterioration and Conservation of Stone, Columbia University, New York.

Wheeler, G.E., 2005, Alkoxysilanes and The Consolidation of Stone, Getty Publications, Los Angeles.

Whitney, D. L., Fayon, A. K., Broz., and Cook. R. F., 2007, Exploring The Relation of Scratch Resistance, Hardness, and Other Physical Properties of Minerals Using Mohs Scale Minerals, J. Geo. Edu., 55(1), 59.

Wu, X., Wen, Z., Xu, X., Wang, X., and Lin, J., 2009, Synthesis and Characterization of $\mathrm{Li} 4 \mathrm{SiO} 4$ Nano-Powders by a Water-Based Sol-Gel Process, J. Nucl. Mater., 392(3), 471-475. 